\title{
Ladders and fan graphs are cycle-antimagic
}

\author{
Martin Bača ${ }^{1}$ (D), Pon Jeyanthi² (D), Narayanaperumal Thillaiammal Muthuraja ${ }^{3}$ (D), \\ Pothukutti Nadar Selvagopal $^{4}$ (D), Andrea Semaničová-Feňovčíková*1 (D) \\ ${ }^{1}$ Department of Applied Mathematics and Informatics, Technical University, Letná 9, Košice, Slovakia \\ ${ }^{2}$ Research Centre, Department of Mathematics, Govindammal Aditanar college for Women, Tiruchendur, \\ Tamilnadu, India \\ ${ }^{3}$ Department of Mathematics, Manonmaniam Sundaranar University PG Extension Centre, Nagercoil, \\ Tamilnadu, India \\ ${ }^{4}$ Al Musanna College of Technology, Sultanate of Oman
}

\begin{abstract}
A simple graph $G=(V, E)$ admits an $H$-covering if every edge in $E$ belongs to at least one subgraph of $G$ isomorphic to a given graph $H$. The graph $G$ admitting an $H$-covering is $(a, d)$ - $H$-antimagic if there exists a bijection $f: V \cup E \rightarrow\{1,2, \ldots,|V|+|E|\}$ such that, for all subgraphs $H^{\prime}$ of $G$ isomorphic to $H$, the $H^{\prime}$-weights, $w t_{f}\left(H^{\prime}\right)=\sum_{v \in V\left(H^{\prime}\right)} f(v)+$ $\sum_{e \in E\left(H^{\prime}\right)} f(e)$, form an arithmetic progression with the initial term $a$ and the common difference $d$. Such a labeling is called super if the smallest possible labels appear on the vertices. In this paper we prove the existence of super $(a, d)$ - $H$-antimagic labelings of fan graphs and ladders for $H$ isomorphic to a cycle.
\end{abstract}

Mathematics Subject Classification (2010). 05C78, 05C70

Keywords. $H$-covering, (super) $(a, d)$ - $H$-antimagic total labeling, cycle-antimagic labeling, ladder, fan graph

\section{Introduction}

Let $G=(V, E)$ be a finite simple graph. An edge-covering of $G$ is a family of subgraphs $H_{1}, H_{2}, \ldots, H_{t}$ such that each edge of $E$ belongs to at least one of the subgraphs $H_{i}$, $i=1,2, \ldots, t$. Then it is said that $G$ admits an $\left(H_{1}, H_{2}, \ldots, H_{t}\right)$-(edge) covering. If every subgraph $H_{i}$ is isomorphic to a given graph $H$, then the graph $G$ admits an $H$-covering. A bijective function $f: V \cup E \rightarrow\{1,2, \ldots,|V|+|E|\}$ is an $(a, d)$-H-antimagic labeling of a graph $G$ admitting an $H$-covering whenever, for all subgraphs $H^{\prime}$ isomorphic to $H$, the $H^{\prime}$-weights

$$
w t_{f}\left(H^{\prime}\right)=\sum_{v \in V\left(H^{\prime}\right)} f(v)+\sum_{e \in E\left(H^{\prime}\right)} f(e)
$$

form an arithmetic progression $a, a+d, a+2 d, \ldots, a+(t-1) d$, where $a>0$ and $d \geq 0$ are two integers, and $t$ is the number of all subgraphs of $G$ isomorphic to $H$. Such a labeling

\footnotetext{
${ }^{*}$ Corresponding Author.

Email addresses: martin.baca@tuke.sk (M. Bača), jeyajeyanthi@rediffmail.com (P. Jeyanthi), bareeshraja@yahoo.com (N.T. Muthu Raja),ps_gopaal@yahoo.co.in (P. Selvagopal), andrea.fenovcikova@tuke.sk (A. Semaničová-Feňovčíková)

Received: 28.02.2018; Accepted: 08.08.2019
} 
is called super if the smallest possible labels appear on the vertices. A graph that admits a (super) $(a, d)$ - $H$-antimagic labeling is called (super) $(a, d)$ - $H$-antimagic. For $d=0$ it is called $H$-magic and $H$-supermagic, respectively.

The $H$-supermagic graphs were first studied by Gutiérrez and Lladó [10] as an extension of the edge-magic and super edge-magic graphs introduced by Kotzig and Rosa [14] and Enomoto et al. [9], respectively. Lladó and Moragas [15] studied the cycle-(super)magic behavior of several classes of connected graphs. Further results on $H$-supermagic labelings are available in [18-21].

The $(a, d)$ - $H$-antimagic labeling was introduced by Inayah et al. [11]. In [12] the super $(a, d)$ - $H$-antimagic labeling for some shackles of a connected graph $H$ was investigated. In [22] it was proved that wheels $W_{n}, n \geq 3$ are super $(a, d)$ - $C_{k}$-antimagic for every $k=3,4, \ldots, n-1, n+1$ and $d=0,1,2$.

The (super) $(a, d)-H$-antimagic labeling is related to a super $d$-antimagic labeling of type $(1,1,0)$ of a plane graph, that is the generalization of a face-magic labeling introduced by Lih [16]. A labeling of type $(1,1,0)$, that is a total labeling, of a plane graph is said to be $d$-antimagic if for every positive integer $s$ the set of weights of all $s$-sided faces is $W_{s}=\left\{a_{s}, a_{s}+d, a_{s}+2 d, \ldots, a_{s}+\left(f_{s}-1\right) d\right\}$ for some integers $a_{s}$ and $d \geq 0$, where $f_{s}$ is the number of the $s$-sided faces. Note that, we allow different sets $W_{s}$ for different $s$. The weight of a face under a labeling of type $(1,1,0)$ is the sum of labels of all the edges and vertices surrounding that face. If $d=0$ then Lih called such labeling as magic [16] and described magic $(0$-antimagic) labelings of type $(1,1,0)$ for wheels, friendship graphs and prisms. For further information on super $d$-antimagic labelings, we refer to $[1,3,6]$.

For $H \cong K_{2}$, a (super) $(a, d)$ - $H$-antimagic labeling is also called a (super) $(a, d)$-edgeantimagic total labeling, introduced in [23] and further studied in $[5,17]$. The vertex version of these labelings for generalized pyramid graphs is given in [2].

The existence of super $(a, d)$ - $H$-antimagic labelings for disconnected graphs is studied in [7]. In [4] it is shown that the disjoint union of multiple copies of a (super) $(a, 1)$-treeantimagic graph is also a (super) $(b, 1)$-tree-antimagic. This leads to a natural question. Whether the similar result holds also for other differences and other $H$-antimagic graphs.

A fan graph $F_{n}, n \geq 2$, is a graph obtained by joining all the vertices of the path $P_{n}$ to a further vertex, called the centre. The vertices on the path are called path vertices, the edges adjacent to the central vertex are called spokes and the remaining edges are called path edges. Thus $F_{n}$ contains $n+1$ vertices, say, $v_{1}, v_{2}, \ldots, v_{n+1}$, and $2 n-1$ edges, say, $v_{n+1} v_{i}, 1 \leq i \leq n$, and $v_{i} v_{i+1}, 1 \leq i \leq n-1$.

A ladder $P_{n} \square P_{2}, n \geq 2$, is a Cartesian product of a path on $n$ vertices and a path on 2 vertices. The ladder $P_{n} \square P_{2}$ contains $2 n$ vertices, say, $v_{1}, v_{2}, \ldots, v_{n}, u_{1}, u_{2}, \ldots, u_{n}$, and $3 n-2$ edges $v_{i} v_{i+1}, 1 \leq i \leq n-1, u_{i} u_{i+1}, 1 \leq i \leq n-1$ and $v_{i} u_{i}, 1 \leq i \leq n$.

In this paper we investigate the super $(a, d)$-H-antimagic labelings of fan graphs and ladders for $H$ isomorphic to a cycle. We also prove some results on the existence of super $(a, d)$-cycle-antimagic labelings of fan graphs for several values of parameter $d$.

In [8] Bača et al. proved the following:

Proposition 1.1 ([8]). The fan $F_{n}, n \geq 3$, admits a super $(a, d)$ - $C_{k}$-antimagic labeling for $k=3,4, \ldots,\left\lfloor\frac{n}{2}\right\rfloor+2$ and $d \in\{1,3, k-7, k+1,2 k-5,2 k-1,3 k-9,3 k-1\}$.

They showed that for a fan graph $F_{n}, n \geq 4$, there exists a super $(a, d)$ - $C_{3}$-antimagic labeling for $d=0,1,2,3,4,5,6,8$ and a super $(a, d)$ - $C_{4}$-antimagic labeling for $d=0,1,2,3,4$, $5,6,7,11$ and they proposed the following open problem.

Open Problem $1([8])$. Find a super $(a, d)$ - $C_{k}$-antimagic labeling of the fan graph $F_{n}$ for $d \neq 1,3, k-7, k+1,2 k-5,2 k-1,3 k-9,3 k-1$.

In [13] the following proposition was proved. 
Proposition $1.2([13])$. The fan graph $F_{n}, n \geq 3$, admits a super $(a, d)$ - $C_{k}$-antimagic labeling for $k=3,4, \ldots,\left\lfloor\frac{n}{2}\right\rfloor+2$ and $d \in\{1,2, k-5, k-4, \ldots, k+2,2 k-5,2 k-1\}$.

In this paper we prove that the fan graphs are super $(a, d)$ - $C_{k}$-antimagic for $d \in$ $\{0,4,5,7\}, k=3,4, \ldots,\left\lfloor\frac{n}{2}\right\rfloor+2$. Further we use the known results for fan graphs to obtain super cycle-antimagic labelings of ladders.

\section{Fan graphs}

Let $n, r$ be positive integers, $2 \leq r \leq n-1$. Let $n=(t-1) r+s$, where $2 \leq r \leq n-1$ and $0 \leq s<r$. Thus $t=\left\lceil\frac{n}{r}\right\rceil$. The set of integers $\{1,2, \ldots, n\}, n \geq 2$, can be arranged as a sequence $\left\{a_{i}^{r, n}\right\}_{i=1}^{n}$ such that the $i^{\text {th }}$ element $a_{i}^{r, n}, i=\alpha r+\beta, 0 \leq \alpha \leq t-1,1 \leq \beta \leq r$, is defined as follows:

$$
a_{i}^{r, n}= \begin{cases}(\beta-1) t+\alpha+1, & \text { if } 0 \leq \alpha \leq t-1,1 \leq \beta \leq s, \\ (\beta-1)(t-1)+s+\alpha+1, & \text { if } 0 \leq \alpha \leq t-2, s+1 \leq \beta \leq r .\end{cases}
$$

That is

$$
\begin{aligned}
& \left\{a_{i}^{r, n}\right\}_{i=1}^{n}= \\
& \{1, \quad t+1, \ldots,(s-1) t+1, s t+1, \quad(s+1) t, \quad \ldots,(r-1) t-r+s+2, \\
& 2, \quad t+2, \ldots,(s-1) t+2, s t+2, \quad(s+1) t+1, \ldots,(r-1) t-r+s+3, \\
& \vdots \quad \vdots \quad \ddots \quad \vdots \quad \ddots \quad \cdot \quad \vdots \\
& t-1,2 t-1, \ldots, s t-1, \quad(s+1) t-1,(s+2) t-2, \ldots, n, \\
& t, \quad 2 t, \quad \ldots, s t\} \text {. }
\end{aligned}
$$

In [13] it was proved that the sequence $\left\{a_{i}^{r, n}\right\}_{i=1}^{n}$ has the property that the sum of any $r$ consecutive members of this sequence differs by 1 from the sum of the foregoing $r$ consecutive members of this sequence.

Proposition 2.1 ([13]). Let $n, r$ be positive integers, $2 \leq r \leq n-1$. The elements of $\{1,2, \ldots, n\}$ can be arranged as a sequence $\left\{a_{i}^{r, n}\right\}_{i=1}^{n}$ such that $\sum_{j=i+1}^{i+r} a_{j+r}^{r, n}-\sum_{j=i}^{i+r-1} a_{j}^{r, n}=$ 1 for $1 \leq i \leq n-r+1$.

We immediately obtain that for $i=1,2, \ldots, n-r+1$

$$
\begin{aligned}
1 & =\sum_{j=i+1}^{i+r} a_{j+r}^{r, n}-\sum_{j=i}^{i+r-1} a_{j}^{r, n}=a_{i+r}^{r, n}-a_{i}^{r, n}, \\
\sum_{j=i}^{i+r-1} a_{j}^{r, n} & =\frac{r(s t+n-t+3)-s(n+1)}{2}-1+j .
\end{aligned}
$$

Next theorem shows that the fan graph admits super cycle-antimagic labelings for differences $d=0,4,5$ and $d=7$.

Theorem 2.2. Let $n \geq 3$ be a positive integer and $3 \leq k \leq\left\lfloor\frac{n}{2}\right\rfloor+2$. Then the fan graph $F_{n}$ admits a super $(a, d)-C_{k}$-antimagic labeling for $d=0,4,5,7$.

Proof. Let $n \geq 3$ be a positive integer and $3 \leq k \leq\left\lfloor\frac{n}{2}\right\rfloor+2$. We consider the total labelings $f_{m}, m=0,4,5,7$, of $F_{n}$ defined in the following way. The vertices are labeled with the numbers $1,2, \ldots, n+1$ such that

$$
\begin{aligned}
f_{m}\left(v_{i}\right) & =a_{i}^{k-1, n}, & & \text { for } i=1,2, \ldots, n \\
f_{5}\left(v_{i}\right) & =n+1-a_{i}^{k-1, n}, & & \text { for } i=1,2, \ldots, n, \\
f_{m}\left(v_{n+1}\right) & =n+1, & & \text { for } m=0,4,5,7,
\end{aligned}
$$

where $a_{i}^{k-1, n}$ is an element of the sequence $\left\{a_{i}^{k-1, n}\right\}_{i=1}^{n}$, see (2.1). 
For $f_{m}, m=0,4,5,7$, we assign numbers $n+2, n+3, \ldots, 3 n$ to the edges of $F_{n}$ in the following way:

$$
\begin{aligned}
f_{m}\left(v_{i} v_{i+1}\right) & =a_{i}^{k-2, n-1}+n+1, & & \text { for } i=1,2, \ldots, n-1 \text { and } m=0,4, \\
f_{m}\left(v_{i} v_{i+1}\right) & =2 a_{i}^{k-2, n-1}+n+1, & & \text { for } i=1,2, \ldots, n-1 \text { and } m=5,7, \\
f_{0}\left(v_{i} v_{n+1}\right) & =3 n+1-i, & & \text { for } i=1,2, \ldots, n, \\
f_{4}\left(v_{i} v_{n+1}\right) & =2 n+i, & & \text { for } i=1,2, \ldots, n, \\
f_{m}\left(v_{i} v_{n+1}\right) & =n+2 i, & & \text { for } i=1,2, \ldots, n \text { and } m=5,7,
\end{aligned}
$$

where $a_{i}^{k-2, n-1}$ is an element of the sequence $\left\{a_{i}^{k-2, n-1}\right\}_{i=1}^{n-1}$, see (2.1). It is easy to see that $f_{m}, m=0,4,5,7$, is a bijection.

Every cycle $C_{k}$ on $k$ vertices in a fan graph $F_{n}$ is of the form $C_{k}^{j}=v_{j} v_{j+1} v_{j+2} \ldots$ $v_{j+k-2} v_{n+1} v_{j}$, where $j=1,2, \ldots, n-k+2$. As $k=3,4, \ldots,\left\lfloor\frac{n}{2}\right\rfloor+2$ every edge of $F_{n}$ belongs at least to one cycle $C_{k}^{j}$.

For the $C_{k}$-weight of the cycle $C_{k}^{j}, j=1,2, \ldots, n-k+2$, under a total labeling $f_{m}$, $m=0,4,5,7$, we get.

$$
\begin{aligned}
w t_{f_{m}}\left(C_{k}^{j}\right)= & \sum_{v \in V\left(C_{k}^{j}\right)} f_{m}(v)+\sum_{e \in E\left(C_{k}^{j}\right)} f_{m}(e) \\
= & \sum_{s=0}^{k-2} f_{m}\left(v_{j+s}\right)+f_{m}\left(v_{n+1}\right)+\sum_{s=0}^{k-3} f_{m}\left(v_{j+s} v_{j+s+1}\right) \\
& +f_{m}\left(v_{j+k-2} v_{n+1}\right)+f_{m}\left(v_{j} v_{n+1}\right) .
\end{aligned}
$$

We consider the difference of weights of cycles $C_{k}^{j+1}$ and $C_{k}^{j}$ for $j=1,2, \ldots, n-k+1$

$$
\begin{aligned}
w t_{f_{m}}\left(C_{k}^{j+1}\right) & -w t_{f_{m}}\left(C_{k}^{j}\right)=f_{m}\left(v_{j+k-1}\right)+f_{m}\left(v_{j+k-2} v_{j+k-1}\right) \\
& +f_{m}\left(v_{j+1} v_{n+1}\right)+f_{m}\left(v_{j+k-1} v_{n+1}\right)-f_{m}\left(v_{j}\right) \\
& -f_{m}\left(v_{j} v_{j+1}\right)-f_{m}\left(v_{j} v_{n+1}\right)-f_{m}\left(v_{j+k-2} v_{n+1}\right) .
\end{aligned}
$$

Using (2.2) and (2.3) we obtain the following:

$$
\begin{aligned}
w t_{f_{0}}\left(C_{k}^{j+1}\right) & -w t_{f_{0}}\left(C_{k}^{j}\right)=a_{j+k-1}^{k-1, n}+\left(a_{j+k-2}^{k-2, n-1}+n+1\right) \\
& +(3 n+1-(j+1))+(3 n+1-(j+k-1))-a_{j}^{k-1, n} \\
& -\left(a_{j}^{k-2, n-1}+n+1\right)-(3 n+1-j)-(3 n+1-(j+k-2)) \\
& =0 .
\end{aligned}
$$

Thus under the labeling $f_{0}$ all the $C_{k}$-weights are the same.

$$
\begin{aligned}
w t_{f_{4}}\left(C_{k}^{j+1}\right) & -w t_{f_{4}}\left(C_{k}^{j}\right)=a_{j+k-1}^{k-1, n}+\left(a_{j+k-2}^{k-2, n-1}+n+1\right)+(2 n+(j+1)) \\
& +(2 n+(j+k-1))-a_{j}^{k-1, n}-\left(a_{j}^{k-2, n-1}+n+1\right) \\
& -(2 n+j)-(2 n+(j+k-2))=4 .
\end{aligned}
$$

Thus, under the labeling $f_{4}$ the $C_{k}$-weights form the arithmetic sequence with the difference 4.

For $f_{5}$ we obtain

$$
\begin{aligned}
w t_{f_{5}}\left(C_{k}^{j+1}\right) & -w t_{f_{5}}\left(C_{k}^{j}\right)=\left(n+1-a_{j+k-1}^{k-1, n}\right)+\left(2 a_{j+k-2}^{k-2, n-1}+n+1\right) \\
& +(n+2(j+1))+(n+2(j+k-1))-\left(n+1-a_{j}^{k-1, n}\right) \\
& -\left(2 a_{j}^{k-2, n-1}+n+1\right)-(n+2 j)-(n+2(j+k-2))=5,
\end{aligned}
$$

which means that the $C_{k}$-weights form the arithmetic sequence with the difference 5 . 
For the labeling $f_{7}$ we get

$$
\begin{aligned}
w t_{f_{7}}\left(C_{k}^{j+1}\right) & -w t_{f_{7}}\left(C_{k}^{j}\right)=a_{j+k-1}^{k-1, n}+\left(2 a_{j+k-2}^{k-2, n-1}+n+1\right)+(n+2(j+1)) \\
& +(n+2(j+k-1))-a_{j}^{k-1, n}-\left(2 a_{j}^{k-2, n-1}+n+1\right) \\
& -(n+2 j)-(n+2(j+k-2))=7 .
\end{aligned}
$$

The $C_{k}$-weights under the total labeling $f_{7}$ form the arithmetic sequence with the difference 7. This concludes the proof.

Figures 1 to 4 give a super $(a, d)$ - $C_{5}$-antimagic labeling of the fan $F_{6}$ for $d=0,4,5$ and $d=7$.

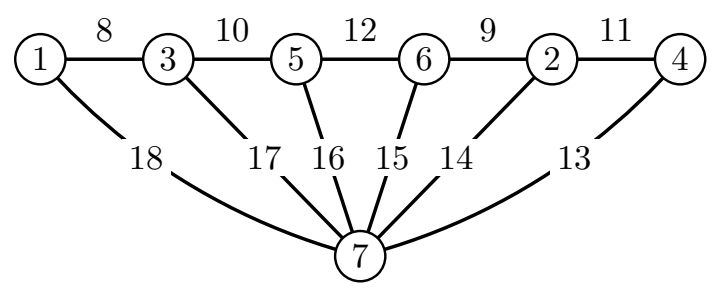

Figure 1. A super $(85,0)-C_{5}$-antimagic labeling of the fan $F_{6}$.

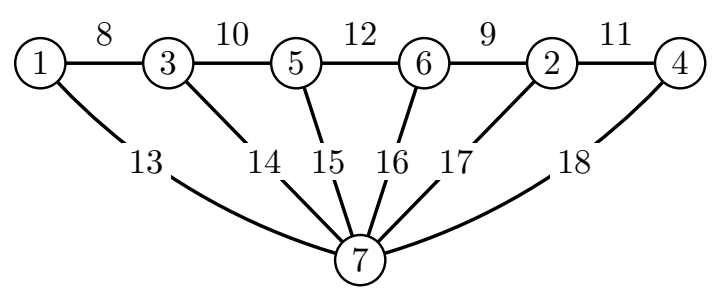

Figure 2. A super $(81,4)-C_{5}$-antimagic labeling of the fan $F_{6}$.

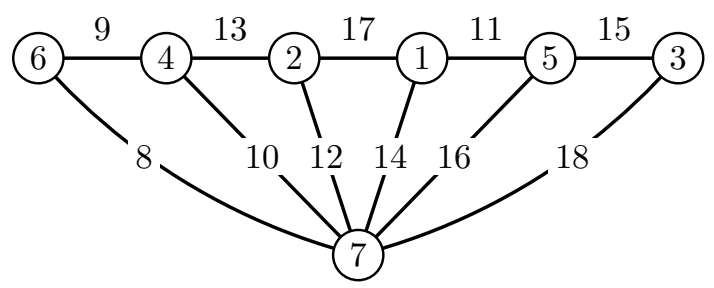

Figure 3. A super $(81,5)-C_{5}$-antimagic labeling of the fan $F_{6}$.

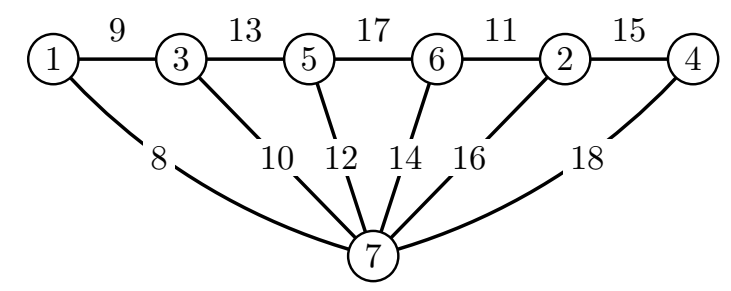

Figure 4. A super $(83,7)-C_{5}$-antimagic labeling of the fan $F_{6}$.

Immediately from Propositions 1.1, 1.2 and Theorem 2.2 we obtain the following result for cycle-antimagicness of fan graphs. 
Theorem 2.3. The fan graph $F_{n}, n \geq 3$, admits a super $(a, d)$ - $C_{k}$-antimagic labeling for $k=3,4, \ldots,\left\lfloor\frac{n}{2}\right\rfloor+2$ and $d \in\{0,1,2,3,4,5,7, k-7, k-5, k-4, \ldots, k+2,2 k-5,2 k-$ $1,3 k-9,3 k-1\}$.

We note that from the constructions of the given labelings described in the proofs of Propositions 1.1, 1.2 and Theorem 2.2, each of such labelings has the property, that the centre of the fan graph $F_{n}$ (the vertex $v_{n+1}$ ) is labeled with the number $n+1$.

\section{Ladders}

In this section we deal with the super cycle-antimagicness of Cartesian product $P_{n} \square P_{2}$. We construct the required labelings from super cycle-antimagic labelings of fans.

Theorem 3.1. The ladder $P_{n} \square P_{2}, n \geq 3$, admits a super $(a, d)-C_{2(k-1)}$-antimagic labeling for $k=3,4, \ldots,\left\lfloor\frac{n}{2}\right\rfloor+2$ and $d \in\{1,2,3,4,5,6,8, k-8, k-6, k-5, \ldots, k+3,2 k-6,2 k-$ $4,2 k-2,2 k, 3 k-10,3 k-8,3 k-2,3 k\}$.

Proof. According to Theorem 2.2 and the results proved in [8] and [13] there exists a super $\left(a_{d}, d\right)-C_{k}$-antimagic labeling $f_{d}$ of fan $F_{n}$ for $k=3,4, \ldots,\left\lfloor\frac{n}{2}\right\rfloor+2$ and $d \in$ $\{0,2,3,4,7, k-7, k-4, k-3, k-2, k, k+1, k+2,2 k-5,2 k-1,3 k-9,3 k-1\}$ having the following properties:

(P1) the vertex $v_{n+1}$ is labeled with the number $n+1$;

(P2) it is possible to denote all subgraphs of $F_{n}$ isomorphic to $C_{k}$ by the symbols $\mathcal{C}_{k}^{i}$, $i=1,2, \ldots, n-k+2$, such that

$$
w t_{f_{d}}\left(\bigodot_{k}^{i}\right)=a_{d}+(i-1) d ;
$$

(P3) and the weight of the cycle $C_{k}$ containing the vertex $v_{1}$ of $F_{n}$ is the smallest one, that is, $v_{1} \in V\left(\mathcal{C}_{k}^{1}\right)$.

We define the total labelings $g_{1}$ and $g_{2}$ of the $P_{n} \square P_{2}$ such that

$$
\begin{array}{rlrl}
g_{m}\left(v_{i}\right) & =f_{d}\left(v_{i}\right), & & \text { for } i=1,2, \ldots, n \text { and } m=1,2, \\
g_{1}\left(u_{i}\right) & =n+i, & & \text { for } i=1,2, \ldots, n-k+2 \\
& & \text { and } v_{i} \in V\left(\mathcal{C}_{k}^{i}\right), \\
& & \mathcal{C}_{k}^{i}=v_{i} v_{i+1} \ldots v_{i+k-2} v_{n+1} v_{i}, \\
g_{2}\left(u_{i}\right) & =2 n+1-i, & & \text { for } i=1,2, \ldots, n-k+2 \\
& & \text { and } v_{i} \in V\left(\mathcal{C}_{k}^{i}\right), \\
g_{1}\left(u_{i}\right) & =n+i, & & \mathcal{C}_{k}^{i}=v_{i} v_{i+1} \ldots v_{i+k-2} v_{n+1} v_{i}, \\
g_{2}\left(u_{i}\right) & =2 n+1-i, & & \text { for } i=n-k+3, n-k+4, \ldots, n, \\
g_{m}\left(v_{i} v_{i+1}\right) & =f_{d}\left(v_{i} v_{i+1}\right)+n-1, & & \text { for } i=1,2, \ldots, n-1 \text { and } m=1,2, \\
g_{m}\left(v_{i} u_{i}\right) & =f_{d}\left(v_{i} v_{n+1}\right)+n-1, & & \text { for } i=1,2, \ldots, n \text { and } m=1,2, \\
g_{1}\left(u_{i} u_{i+1}\right) & =6 n-g_{1}\left(u_{i+1}\right), & & \text { for } i=1,2, \ldots, n-1, \\
g_{2}\left(u_{i} u_{i+1}\right) & =6 n-1-g_{2}\left(u_{i+1}\right), & & \text { for } i=1,2, \ldots, n-1 .
\end{array}
$$

According to Properties (P1) and (P3) the labeling $g_{m}, m=1,2$, is a bijective mapping from the set $\{1,2, \ldots, 5 n-2\}$ and the smallest possible numbers are used to label the vertices of $P_{n} \square P_{2}$.

We denote the $C_{2(k-1)}$ cycle $v_{j} v_{j+1} \ldots v_{j+k-2} u_{j+k-2} u_{j+k-3} \ldots u_{j} v_{j}, j=1,2, \ldots, n-$ $k+2$, in $P_{n} \square P_{2}$ by the symbol $C_{2(k-1)}^{j}$ if $\mathcal{C}_{k}^{j}=v_{j} v_{j+1} v_{j+2} \ldots v_{j+k-2} v_{n+1} v_{j}$ is the cycle in $F_{n}$. 
For the $C_{2(k-1)}$-weight of the cycle $C_{2(k-1)}^{j}, j=1,2, \ldots, n-k+2$, in $P_{n} \square P_{2}$ under a total labeling $g_{m}, m=1,2$, we get

$$
\begin{aligned}
w t_{g_{m}}\left(C_{2(k-1)}^{j}\right)= & \sum_{v \in V\left(C_{2(k-1)}^{j}\right)} g_{m}(v)+\sum_{e \in E\left(C_{2(k-1)}^{j}\right)} g_{m}(e) \\
= & \sum_{s=0}^{k-2} g_{m}\left(v_{j+s}\right)+\sum_{s=0}^{k-2} g_{m}\left(u_{j+s}\right)+\sum_{s=0}^{k-3} g_{m}\left(v_{j+s} v_{j+s+1}\right) \\
& +\sum_{s=0}^{k-3} g_{m}\left(u_{j+s} u_{j+s+1}\right)+g_{m}\left(v_{j} u_{j}\right)+g_{m}\left(v_{j+k-2} u_{j+k-2}\right) .
\end{aligned}
$$

Using Property (P2) we obtain

$$
\begin{aligned}
& \left.w t_{g_{1}}\left(C_{2(k-1)}^{j}\right)=\sum_{s=0}^{k-2} g_{1}\left(v_{j+s}\right)+\sum_{s=0}^{k-2} g_{1}\left(u_{j+s}\right)+\sum_{s=0}^{k-3} g_{1}\left(v_{j+s} v_{j+s+1}\right)\right) \\
& +\sum_{s=0}^{k-3} g_{1}\left(u_{j+s} u_{j+s+1}\right)+g_{1}\left(v_{j} u_{j}\right)+g_{1}\left(v_{j+k-2} u_{j+k-2}\right) \\
& =\sum_{s=0}^{k-2} f_{d}\left(v_{j+s}\right)+\sum_{s=0}^{k-2} g_{1}\left(u_{j+s}\right) \\
& +\sum_{s=0}^{k-3}\left(f_{d}\left(v_{j+s} v_{j+s+1}\right)+n-1\right)+\sum_{s=0}^{k-3}\left(6 n-g_{1}\left(u_{j+s+1}\right)\right) \\
& +\left(f_{d}\left(v_{j} v_{n+1}\right)+n-1\right)+\left(f_{d}\left(v_{j+k-2} v_{n+1}\right)+n-1\right) \\
& =\sum_{s=0}^{k-2} f_{d}\left(v_{j+s}\right)+g_{1}\left(u_{j}\right)+\sum_{s=0}^{k-3} g_{1}\left(u_{j+s+1}\right) \\
& +\sum_{s=0}^{k-3} f_{d}\left(v_{j+s} v_{j+s+1}\right)+(k-2)(n-1)+(k-2) 6 n \\
& -\sum_{s=0}^{k-3} g_{1}\left(u_{j+s+1}\right)+f_{d}\left(v_{j} v_{n+1}\right)+f_{d}\left(v_{j+k-2} v_{n+1}\right) \\
& +2 n-2 \\
& =\left(\sum_{s=0}^{k-2} f_{d}\left(v_{j+s}\right)+\sum_{s=0}^{k-3} f_{d}\left(v_{j+s} v_{j+s+1}\right)+f_{d}\left(v_{j} v_{n+1}\right)\right. \\
& \left.+f_{d}\left(v_{j+k-2} v_{n+1}\right)\right)+g_{1}\left(u_{j}\right)+n(7 k-12)-k \\
& =\left(w t_{f_{d}}\left(\mathfrak{C}_{k}^{j}\right)-(n+1)\right)+g_{1}\left(u_{j}\right)+n(7 k-12)-k \\
& =\left(a_{d}+(j-1) d\right)+(n+j)+n(7 k-13)-k-1 \\
& =a_{d}+n(7 k-12)-k-1-d+j(d+1) \text {. }
\end{aligned}
$$


For the $C_{2(k-1)}$-weights under the labeling $g_{2}$ we get

$$
\begin{aligned}
w t_{g_{2}}\left(C_{2(k-1)}^{j}\right)= & \sum_{s=0}^{k-2} g_{2}\left(v_{j+s}\right)+\sum_{s=0}^{k-2} g_{2}\left(u_{j+s}\right)+\sum_{s=0}^{k-3} g_{2}\left(v_{j+s} v_{j+s+1}\right) \\
& +\sum_{s=0}^{k-3} g_{2}\left(u_{j+s} u_{j+s+1}\right)+g_{2}\left(v_{j} u_{j}\right)+g_{2}\left(v_{j+k-2} u_{j+k-2}\right) \\
= & \sum_{s=0}^{k-2} f_{d}\left(v_{j+s}\right)+\sum_{s=0}^{k-2} g_{2}\left(u_{j+s}\right) \\
& +\sum_{s=0}^{k-3}\left(f_{d}\left(v_{j+s} v_{j+s+1}\right)+n-1\right) \\
& +\sum_{s=0}^{k-3}\left(6 n-1-g_{2}\left(u_{j+s+1}\right)\right) \\
& +\left(f_{d}\left(v_{j} v_{n+1}\right)+n-1\right)+\left(f_{d}\left(v_{j+k-2} v_{n+1}\right)+n-1\right) \\
= & \sum_{s=0}^{k-2} f_{d}\left(v_{j+s}\right)+g_{2}\left(u_{j}\right)+\sum_{s=0}^{k-3} g_{2}\left(u_{j+s+1}\right) \\
& +\sum_{s=0}^{k-3} f_{d}\left(v_{j+s} v_{j+s+1}\right)+(k-2)(n-1)+(k-2)(6 n-1) \\
& -\sum_{s=0}^{k-3} g_{2}\left(u_{j+s+1}\right)+f_{d}\left(v_{j} v_{n+1}\right)+f_{d}\left(v_{j+k-2} v_{n+1}\right) \\
& +2 n-2 \\
= & \left(\sum_{s=0}^{k-2} f_{d}\left(v_{j+s}\right)+\sum_{s=0}^{k-3} f_{d}\left(v_{j+s} v_{j+s+1}\right)+f_{d}\left(v_{j} v_{n+1}\right)\right. \\
& \left.+f_{d}\left(v_{j+k-2} v_{n+1}\right)\right)+g_{2}\left(u_{j}\right)+n(7 k-12)-2 k+2 \\
= & \left.a_{d}+n t_{d}\left(\mathfrak{C}_{k}^{j}\right)-(n+1)\right)+g_{2}\left(u_{j}\right)+n(7 k-12)-2 k+2 \\
& +n-11)-2 k+2-d+j(d-1) . \\
& \\
& k n+13)-2 k+1 \\
&
\end{aligned}
$$

As $d \in\{0,2,3,4,7, k-7, k-5, k-4, k-3, k-2, k, k+1, k+2,2 k-5,2 k-1,3 k-9,3 k-1\}$, we immediately obtain that the ladder $P_{n} \square P_{2}, n \geq 3$, admits a super $\left(a, d^{*}\right)-C_{2(k-1)}$-antimagic labeling for $k=3,4, \ldots,\left\lfloor\frac{n}{2}\right\rfloor+2$ and $d^{*} \in\{1,2,3,4,5,6,8, k-8, k-6, k-5, \ldots, k+3,2 k-$ $6,2 k-4,2 k-2,2 k, 3 k-10,3 k-8,3 k-2,3 k\}$.

Figure 5 illustrates a super $(218,1)$ - $C_{8}$-antimagic labeling of the ladder $P_{6} \square P_{2}$ obtained from $(85,0)-C_{5}$-antimagic labeling of the fan $F_{6}$, (see Figure 1 ), by using the construction described in the previous theorem. 


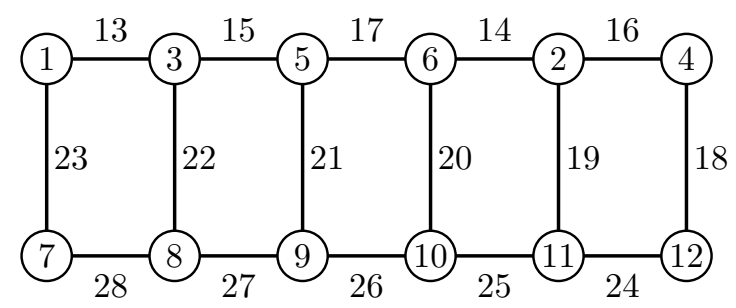

Figure 5. A super $(218,1)-C_{8}$-antimagic labeling of the ladder $P_{6} \square P_{2}$.

The following theorems show that the ladder also admits super cycle-antimagic labelings with differences $d=0,10,12,14,16$.

Theorem 3.2. Let $n \geq 3$ be a positive integer and $2 \leq k \leq\left\lfloor\frac{n}{2}\right\rfloor+1$. Then the ladder $P_{n} \square P_{2}$ admits a super $C_{2 k}$-magic labeling.

Proof. Let $n \geq 3$ be a positive integer and $2 \leq k \leq\left\lfloor\frac{n}{2}\right\rfloor+1$. We consider the total labeling $f$ of ladder $P_{n} \square P_{2}$ defined in the following way.

$$
\begin{aligned}
f\left(v_{i}\right) & =i, & & \text { for } i=1,2, \ldots, n, \\
f\left(u_{i}\right) & =n+i, & & \text { for } i=1,2, \ldots, n, \\
f\left(v_{i} v_{i+1}\right) & =3 n-i, & & \text { for } i=1,2, \ldots, n-1, \\
f\left(u_{i} u_{i+1}\right) & =4 n-1-i, & & \text { for } i=1,2, \ldots, n-1, \\
f\left(v_{i} u_{i}\right) & =5 n-1-i, & & \text { for } i=1,2, \ldots, n .
\end{aligned}
$$

It is easy to see that the labeling $f$ is a bijection and the vertices are labeled with numbers $1,2, \ldots, 2 n$.

Every cycle $C_{2 k}$ on $2 k$ vertices in $P_{n} \square P_{2}$ is of the form $C_{2 k}^{j}=v_{j} v_{j+1} v_{j+2} \ldots v_{j+k-1}$ $u_{j+k-1} u_{j+k-2} \ldots u_{j} v_{j}$, where $j=1,2, \ldots, n-k+1$. As $k=2,3, \ldots,\left\lfloor\frac{n}{2}\right\rfloor+1$ every edge of $P_{n} \square P_{2}$ belongs at least to one cycle $C_{2 k}^{j}$.

For the $C_{2 k}$-weight of the cycle $C_{2 k}^{j}, j=1,2, \ldots, n-k+1$, under the total labeling $f$ we get.

$$
\begin{aligned}
w t_{f}\left(C_{2 k}^{j}\right)= & \sum_{v \in V\left(C_{2 k}^{j}\right)} f(v)+\sum_{e \in E\left(C_{2 k}^{j}\right)} f(e) \\
= & \sum_{s=0}^{k-1} f\left(v_{j+s}\right)+\sum_{s=0}^{k-1} f\left(u_{j+s}\right)+\sum_{s=0}^{k-2} f\left(v_{j+s} v_{j+s+1}\right) \\
& +\sum_{s=0}^{k-2} f\left(u_{j+s} u_{j+s+1}\right)+f\left(v_{j+k-1} u_{j+k-1}\right)+f\left(v_{j} u_{j}\right) .
\end{aligned}
$$

We consider the difference of weights of cycles $C_{2 k}^{j+1}$ and $C_{2 k}^{j}$ for $j=1,2, \ldots, n-k$

$$
\begin{aligned}
w t_{f}\left(C_{2 k}{ }^{j+1}\right)-w t_{f}\left(C_{2 k}^{j}\right)=f\left(v_{j+k}\right)+f\left(u_{j+k}\right)+f\left(v_{j+k-1} v_{j+k}\right) \\
\quad+f\left(u_{j+k-1} u_{j+k}\right)+f\left(v_{j+1} u_{j+1}\right)+f\left(v_{j+k} u_{j+k}\right)-f\left(v_{j}\right) \\
\quad-f\left(u_{j}\right)-f\left(v_{j} v_{j+1}\right)-f\left(u_{j} u_{j+1}\right)-f\left(v_{j} u_{j}\right)-f\left(v_{j+k-1} u_{j+k-1}\right) \\
=(j+k)+(n+j+k)+(3 n-(j+k-1)) \\
\quad+(4 n-1-(j+k-1))+(5 n-1-(j+1)) \\
\quad+(5 n-1-(j+k))-j-(n+j)-(3 n-j)-(4 n-1-j) \\
\quad-(5 n-1-j)-(5 n-1-(j+k-1))=0 .
\end{aligned}
$$

Thus the $C_{2 k}$-weights are the same. This means that the labeling $f$ is super $C_{2 k}$-magic. This concludes the proof. 
Figure 6 depicts a super $C_{8}$-magic labeling of the ladder $P_{6} \square P_{2}$.

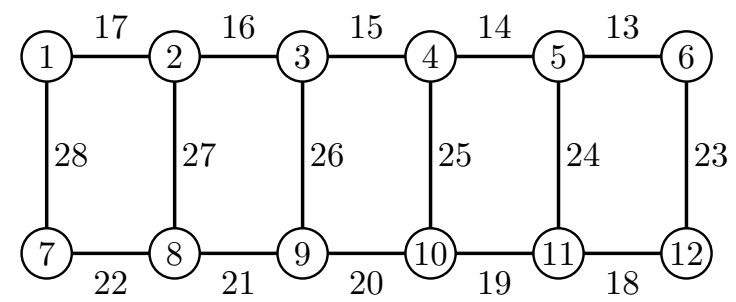

Figure 6. A super $C_{8}$-magic labeling of the ladder $P_{6} \square P_{2}$.

Theorem 3.3. Let $n \geq 3$ be a positive integer and $2 \leq k \leq\left\lfloor\frac{n}{2}\right\rfloor+1$. Then the ladder $P_{n} \square P_{2}$ admits a super $(a, 10)-C_{2 k}$-antimagic labeling.

Proof. Let $n \geq 3$ be a positive integer and $2 \leq k \leq\left\lfloor\frac{n}{2}\right\rfloor+1$. We consider the total labeling $f$ of ladder $P_{n} \square P_{2}$ defined in the following way. The vertices are labeled with numbers $1,2, \ldots, 2 n$ such that

$$
\begin{array}{ll}
f\left(v_{i}\right)=2 a_{i}^{k, n}, & \text { for } i=1,2, \ldots, n, \\
f\left(u_{i}\right)=2 a_{i}^{k, n}-1, & \text { for } i=1,2, \ldots, n,
\end{array}
$$

where $a_{i}^{k, n}$ is an element of the sequence $\left\{a_{i}^{k, n}\right\}_{i=1}^{n}$, see (2.1).

The labeling $f$ assigns numbers $2 n+1,2 n+2, \ldots, 5 n-2$ to the edges of $P_{n} \square P_{2}$ in the following way:

$$
\begin{aligned}
f\left(v_{i} v_{i+1}\right) & =2 a_{i}^{k-1, n-1}+2 n, & & \text { for } i=1,2, \ldots, n-1, \\
f\left(u_{i} u_{i+1}\right) & =2 a_{i}^{k-1, n-1}+2 n-1, & & \text { for } i=1,2, \ldots, n-1, \\
f\left(v_{i} u_{i}\right) & =4 n-2+i, & & \text { for } i=1,2, \ldots, n,
\end{aligned}
$$

where $a_{i}^{k-1, n-1}$ is an element of the sequence $\left\{a_{i}^{k-1, n-1}\right\}_{i=1}^{n-1}$, see (2.1). It is easy to see that the labeling $f$ is a bijection.

As in the proof of the previous theorem we consider the difference of weights of cycles $C_{2 k}^{j+1}$ and $C_{2 k}^{j}$ for $j=1,2, \ldots, n-k$ and we use $(2.2)$

$$
\begin{aligned}
w t_{f}\left(C_{2 k}^{j+1}\right)-w t_{f}\left(C_{2 k}^{j}\right)=2 a_{j+k}^{k, n}+\left(2 a_{j+k}^{k, n}-1\right)+\left(2 a_{j+k-1}^{k-1, n-1}+2 n\right) \\
\quad+\left(2 a_{j+k-1}^{k-1, n-1}+2 n-1\right)+(4 n-2+(j+1)) \\
\quad+(4 n-2+(j+k))-2 a_{j}^{k, n}-\left(2 a_{j}^{k, n}-1\right)-\left(2 a_{j}^{k-1, n-1}+2 n\right) \\
\quad-\left(2 a_{j}^{k-1, n-1}+2 n-1\right)-(4 n-2+j)-(4 n-2+(j+k-1)) \\
=10 .
\end{aligned}
$$

The $C_{2 k}$-weights under the total labeling $f$ form the arithmetic sequence with the difference 10. This concludes the proof.

Figure 7 illustrates a super $(210,10)-C_{8}$-antimagic labeling of the ladder $P_{6} \square P_{2}$. 


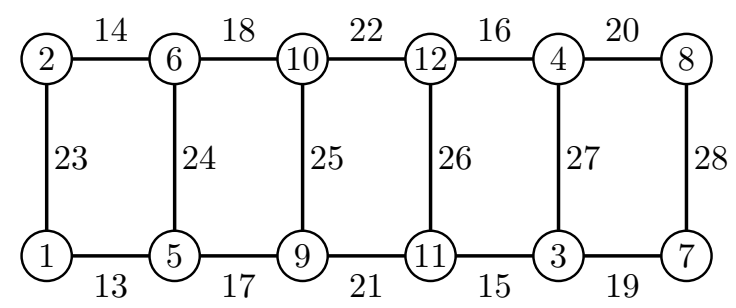

Figure 7. A super $(210,10)-C_{8}$-antimagic labeling of the ladder $P_{6} \square P_{2}$.

Theorem 3.4. Let $n \geq 3$ be a positive integer and $2 \leq k \leq\left\lfloor\frac{n}{2}\right\rfloor+1$. Then the ladder $P_{n} \square P_{2}$ admits a super $(a, d)$ - $C_{2 k}$-antimagic labeling for $d=12,14,16$.

Proof. Let $n \geq 3$ be a positive integer and $2 \leq k \leq\left\lfloor\frac{n}{2}\right\rfloor+1$. We consider the total labeling $f_{m}, m=12,14,16$, of ladder $P_{n} \square P_{2}$ defined in the following way. The vertices are labeled with numbers $1,2, \ldots, 2 n$ such that

$$
\begin{array}{ll}
f_{m}\left(v_{i}\right)=a_{i}^{k, n}, & \text { for } i=1,2, \ldots, n \text { and } m=12,14, \\
f_{16}\left(v_{i}\right)=2 a_{i}^{k, n}, & \text { for } i=1,2, \ldots, n, \\
f_{12}\left(u_{i}\right)=2 n+1-a_{i}^{k, n}, & \text { for } i=1,2, \ldots, n, \\
f_{14}\left(u_{i}\right)=a_{i}^{k, n}+n, & \text { for } i=1,2, \ldots, n, \\
f_{16}\left(u_{i}\right)=2 a_{i}^{k, n}-1, & \text { for } i=1,2, \ldots, n,
\end{array}
$$

where $a_{i}^{k, n}$ is an element of the sequence $\left\{a_{i}^{k, n}\right\}_{i=1}^{n}$, see (2.1).

The labeling $f_{m}$ assigns numbers $2 n+1,2 n+2, \ldots, 5 n-2$ to the edges of $P_{n} \square P_{2}$ in the following way

$$
\begin{array}{cl}
f_{m}\left(v_{i} v_{i+1}\right)=3 a_{i}^{k-1, n-1}+2 n, & \text { for } i=1,2, \ldots, n-1 \\
f_{m}\left(u_{i} u_{i+1}\right)=3 a_{i}^{k-1, n-1}+2 n-1, & \text { and } m=12,14,16, \\
f_{m}\left(v_{i} u_{i}\right)=2 n-2+3 i, & \text { for } i=1,2, \ldots, n-1 \\
& \text { and } m=12,14,16, \\
& \text { for } i=1,2, \ldots, n \text { and } m=12,14,16,
\end{array}
$$

where $a_{i}^{k-1, n-1}$ is an element of the sequence $\left\{a_{i}^{k-1, n-1}\right\}_{i=1}^{n-1}$, see (2.1). It is easy to see that the labeling $f_{m}$ is a bijection.

Again, we consider the difference of weights of cycles $C_{2 k}^{j+1}$ and $C_{2 k}^{j}$ for $j=1,2, \ldots, n-k$, under the labelings $f_{m}, m=12,14,16$.

For $m=12$ we get

$$
\begin{aligned}
w t_{f_{12}}\left(C_{2 k}^{j+1}\right) & -w t_{f_{12}}\left(C_{2 k}^{j}\right)=a_{j+k}^{k, n}+\left(2 n+1-a_{j+k}^{k, n}\right)+\left(3 a_{j+k-1}^{k-1, n-1}+2 n\right) \\
& +\left(3 a_{j+k-1}^{k-1, n-1}+2 n-1\right)+(2 n-2+3(j+1)) \\
& +(2 n-2+3(j+k))-a_{j}^{k, n}-\left(2 n+1-a_{j}^{k, n}\right) \\
& -\left(3 a_{j}^{k-1, n-1}+2 n\right)-\left(3 a_{j}^{k-1, n-1}+2 n-1\right) \\
& -(2 n-2+3 j)-(2 n-2+3(j+k-1))=12 .
\end{aligned}
$$

The $C_{2 k}$-weights under the total labeling $f_{12}$ form the arithmetic sequence with the difference 12 . 
If $m=14$ then

$$
\begin{aligned}
w t_{f_{14}}\left(C_{2 k}^{j+1}\right) & -w t_{f_{14}}\left(C_{2 k}^{j}\right)=a_{j+k}^{k, n}+\left(a_{j+k}^{k, n}+n\right)+\left(3 a_{j+k-1}^{k-1, n-1}+2 n\right) \\
& +\left(3 a_{j+k-1}^{k-1, n-1}+2 n-1\right)+(2 n-2+3(j+1)) \\
& +(2 n-2+3(j+k))-a_{j}^{k, n}-\left(a_{j}^{k, n}+n\right) \\
& -\left(3 a_{j}^{k-1, n-1}+2 n\right)-\left(3 a_{j}^{k-1, n-1}+2 n-1\right) \\
& -(2 n-2+3 j)-(2 n-2+3(j+k-1))=14 .
\end{aligned}
$$

The $C_{2 k}$-weights under the total labeling $f_{14}$ form the arithmetic sequence with the difference 14 .

Finally, for the labeling $f_{16}$ we obtain

$$
\begin{aligned}
w t_{f_{16}}\left(C_{2 k}^{j+1}\right) & -w t_{f_{16}}\left(C_{2 k}^{j}\right)=2 a_{j+k}^{k, n}+\left(2 a_{j+k}^{k, n}-1\right)+\left(3 a_{j+k-1}^{k-1, n-1}+2 n\right) \\
& +\left(3 a_{j+k-1}^{k-1, n-1}+2 n-1\right)+(2 n-2+3(j+1)) \\
& +(2 n-2+3(j+k))-2 a_{j}^{k, n}-\left(2 a_{j}^{k, n}-1\right) \\
& -\left(3 a_{j}^{k-1, n-1}+2 n\right)-\left(3 a_{j}^{k-1, n-1}+2 n-1\right) \\
& -(2 n-2+3 j)-(2 n-2+3(j+k-1))=16 .
\end{aligned}
$$

Thus the $C_{2 k}$-weights under the total labeling $f_{16}$ form the arithmetic sequence with the difference 16. This concludes the proof.

Figures 8,9 and 10 give a super $(a, d)$ - $C_{8}$-antimagic labeling of the ladder $P_{6} \square P_{2}$ for $d=12,14$ and $d=16$.

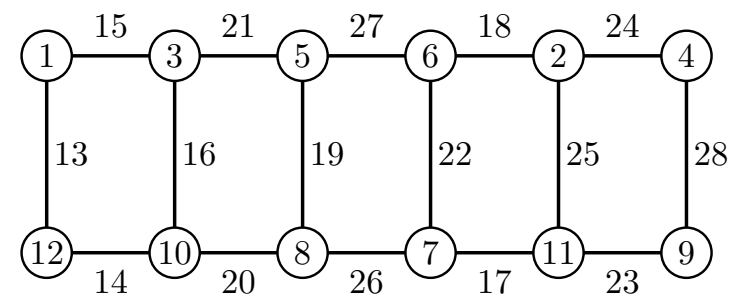

Figure 8. A super $(210,12)-C_{8}$-antimagic labeling of the ladder $P_{6} \square P_{2}$.

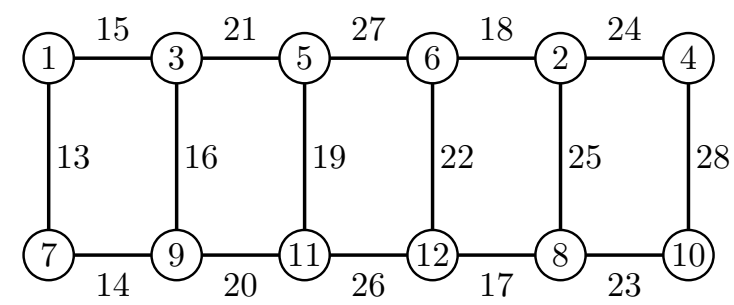

Figure 9. A super $(212,14)-C_{8}$-antimagic labeling of the ladder $P_{6} \square P_{2}$. 


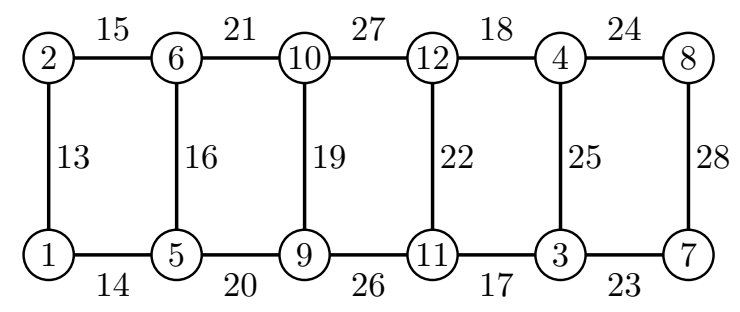

Figure 10. A super $(214,16)-C_{8}$-antimagic labeling of the ladder $P_{6} \square P_{2}$.

\section{Conclusion}

In this paper we prove the existence of super $(a, d)$-cycle-antimagic labelings of fan graphs and ladders. Combining the results obtained in this paper and in $[8,13]$ we get that the fan graph $F_{n}, n \geq 3$, admits a super $(a, d)$ - $C_{k}$-antimagic labeling for $k=3,4, \ldots,\left\lfloor\frac{n}{2}\right\rfloor+$ 2 and $d \in\{0,1,2,3,4,5,7, k-7, k-5, k-4, \ldots, k+2,2 k-5,2 k-1,3 k-9,3 k-1\}$. Further, we prove that the ladder $P_{n} \square P_{2}, n \geq 3$, admits a super $(a, d)-C_{2(k-1)}$-antimagic labeling for $k=3,4, \ldots,\left\lfloor\frac{n}{2}\right\rfloor+2$ and $d \in\{0,1,2,3,4,5,6,8,10,12,14,16, k-8, k-6, k-5, \ldots, k+$ $3,2 k-6,2 k-4,2 k-2,2 k, 3 k-10,3 k-8,3 k-2,3 k\}$.

Though there are results on super $(a, d)$-cycle-antimagic labelings of fan graphs and ladders for various differences $d$, still some values of $d$ for which the problem of existence of the corresponding labelings is not solved is a scope for further research.

Acknowledgment. This work was supported by the Slovak Research and Development Agency under the contract No. APVV-15-0116 and by VEGA 1/0233/18.

\section{References}

[1] A. Ahmad, M. Bača, M. Lascsáková and A. Semaničová-Feňovčíková, Super magic and antimagic labelings of disjoint union of plane graphs, Sci. Int. 24 (1), 21-25, 2012.

[2] S. Arumugam, M. Miller, O. Phanalasy and J. Ryan, Antimagic labeling of generalized pyramid graphs, Acta Math. Sinica - English Series, 30, 283-290, 2014.

[3] M. Bača, L. Brankovic and A. Semaničová-Feňovčíková, Labelings of plane graphs containing Hamilton path, Acta Math. Sinica - English Series, 27 (4), 701-714, 2011.

[4] M. Bača, Z. Kimáková, A. Semaničová-Feňovčíková and M.A. Umar, Tree-antimagicness of disconnected graphs, Mathematical Problems in Engineering, 2015, Article ID 504251, 1-4, 2015.

[5] M. Bača and M. Miller, Super edge-antimagic graphs: A wealth of problems and some solutions, Brown Walker Press, Boca Raton, Florida, 2008.

[6] M. Bača, M. Miller, O. Phanalasy and A. Semaničová-Feňovčíková, Super d-antimagic labelings of disconnected plane graphs, Acta Math. Sinica - English Series, 26 (12), 2283-2294, 2010.

[7] M. Bača, M. Miller, J. Ryan and A. Semaničová-Feňovčíková, On H-antimagicness of disconnected graphs, Bull. Aust. Math. Soc. 94 (2), 201-207, 2016.

[8] M. Bača, A. Ovais, A. Semaničová-Feňovčíková and M.A. Umar, Fans are cycleantimagic, Australas. J. Combin. 68 (1), 94-105, 2017.

[9] H. Enomoto, A.S. Lladó, T. Nakamigawa and G. Ringel, Super edge-magic graphs, SUT J. Math. 34, 105-109, 1998.

[10] A. Gutiérrez and A.S. Lladó, Magic coverings, J. Combin. Math. Combin. Comput. $\mathbf{5 5}, 43-56,2005$.

[11] N. Inayah, A.N.M. Salman and R. Simanjuntak, On $(a, d)$-H-antimagic coverings of graphs, J. Combin. Math. Combin. Comput. 71, 273-281, 2009. 
[12] N. Inayah, R. Simanjuntak, A.N.M. Salman and K.I.A. Syuhada, On $(a, d)-H$ antimagic total labelings for shackles of a connected graph $H$, Australasian J. Combin. 57, 127-138, 2013.

[13] P. Jeyanthi, N.T. Muthuraja, A. Semaničová-Feňovčíková and S.J. Dharshikha, More classes of super cycle-antimagic graphs, Australas. J. Combin. 67 (1), 46-64, 2017.

[14] A. Kotzig and A. Rosa, Magic valuations of finite graphs, Canad. Math. Bull. 13, 451-461, 1970.

[15] A. Lladó and J. Moragas, Cycle-magic graphs, Discrete Math. 307, 2925-2933, 2007.

[16] K.W. Lih, On magic and consecutive labelings of plane graphs, Utilitas Math. 24, 165-197, 1983.

[17] A.M. Marr and W.D. Wallis, Magic Graphs, Birkhäuser, New York, 2013.

[18] T.K. Maryati, A.N.M. Salman and E.T. Baskoro, Supermagic coverings of the disjoint union of graphs and amalgamations, Discrete Math. 313, 397-405, 2013.

[19] T.K. Maryati, A.N.M. Salman, E.T. Baskoro, J. Ryan and M. Miller, On Hsupermagic labelings for certain shackles and amalgamations of a connected graph, Utilitas Math. 83, 333-342, 2010.

[20] A.A.G. Ngurah, A.N.M. Salman and L. Susilowati, $H$-supermagic labelings of graphs, Discrete Math. 310, 1293-1300, 2010.

[21] A.N.M. Salman, A.A.G. Ngurah and N. Izzati, On (super)-edge-magic total labelings of subdivision of stars $S_{n}$, Utilitas Math. 81, 275-284, 2010.

[22] A. Semaničová-Feňovčíková, M. Bača, M. Lascsáková, M. Miller and J. Ryan, Wheels are cycle-antimagic, Electron. Notes Discrete Math. 48, 11-18, 2015.

[23] R. Simanjuntak, M. Miller and F. Bertault, Two new $(a, d)$-antimagic graph labelings, Proc. Eleventh Australas. Workshop Combin. Alg. (AWOCA), 179-189, 2000. 